\title{
Brain computer interface learning for systems based on electrocorticography and intracortical microelectrode arrays
}

\author{
Shivayogi V. Hiremath ${ }^{1,2}$, Weidong Chen ${ }^{1,3}$, Wei Wang ${ }^{1,4,5,6 *}$, Stephen Foldes ${ }^{1,2,6}$, \\ Ying Yang ${ }^{1,6}$, Elizabeth C. Tyler-Kabara ${ }^{1,4,7}$, Jennifer L. Collinger ${ }^{1,2,4,6}$ and \\ Michael L. Boninger ${ }^{1,2,4,5}$
}

\begin{abstract}
' Department of Physical Medicine and Rehabilitation, University of Pittsburgh, Pittsburgh, PA, USA, ${ }^{2}$ Department of Veterans Affairs, Human Engineering Research Laboratories, Pittsburgh, PA, USA, ${ }^{3}$ Qiushi Academy for Advanced Studies (QAAS), Zhejiang University, Hangzhou, China, ${ }^{4}$ Department of Bioengineering, University of Pittsburgh, Pittsburgh, PA, USA, ${ }^{5}$ Clinical and Translational Science Institute, University of Pittsburgh, Pittsburgh, PA, USA, ${ }^{6}$ Center for the Neural Basis of Cognition, Carnegie Mellon University and the University of Pittsburgh, Pittsburgh, PA, USA, ${ }^{7}$ Department of Neurological Surgery, University of Pittsburgh, Pittsburgh, PA, USA
\end{abstract}

OPEN ACCESS

Edited by:

Martin Oudega,

University of Pittsburgh, USA

Reviewed by:

Fabien Lotte,

French Institute for Research in Computer Science and Automation,

France

Aysegul Gunduz,

University of Florida, USA

Ramana Vinjamuri,

Stevens Institute of Technology, USA

${ }^{*}$ Correspondence: Wei Wang

Department of Physical Medicine and Rehabilitation, University of Pittsburgh, 3471 Fifth Ave., Suite 202, Pittsburgh, PA 15213, USA wangwei3@pitt.edu

Received: 19 November 2014 Accepted: 20 May 2015 Published: 10 June 2015

Citation:

Hiremath SV, Chen W, Wang W, Foldes S, Yang Y, Tyler-Kabara EC, Collinger $J L$ and Boninger ML (2015) Brain computer interface learning for systems based on electrocorticography and intracortical microelectrode arrays.

Front. Integr. Neurosci. 9:40. doi: 10.3389/fnint.2015.00040
A brain-computer interface $(\mathrm{BCl})$ system transforms neural activity into control signals for external devices in real time. $\mathrm{A} \mathrm{BCl}$ user needs to learn to generate specific cortical activity patterns to control external devices effectively. We call this process $\mathrm{BCl}$ learning, and it often requires significant effort and time. Therefore, it is important to study this process and develop novel and efficient approaches to accelerate $\mathrm{BCl}$ learning. This article reviews major approaches that have been used for $\mathrm{BCl}$ learning, including computer-assisted learning, co-adaptive learning, operant conditioning, and sensory feedback. We focus on BCls based on electrocorticography and intracortical microelectrode arrays for restoring motor function. This article also explores the possibility of brain modulation techniques in promoting $\mathrm{BCl}$ learning, such as electrical cortical stimulation, transcranial magnetic stimulation, and optogenetics. Furthermore, as proposed by recent $\mathrm{BCl}$ studies, we suggest that $\mathrm{BCl}$ learning is in many ways analogous to motor and cognitive skill learning, and therefore skill learning should be a useful metaphor to model BCl learning.

Keywords: $\mathrm{BCl}$ learning, $\mathrm{BCl}$ mapping, brain control, human-computer interfaces, motor learning, cognitive skill learning

\section{Introduction}

Brain-computer interface (BCI) technology aims to establish a direct communication pathway between the brain and external devices. BCI technology has the potential to assist, augment, or repair human sensorimotor and other cognitive functions, thus improving the quality of life for individuals with disabilities (Schwartz et al., 2006; Daly and Wolpaw, 2008; Donoghue, 2008; Moran, 2010; Wang et al., 2010c). During the last few decades, significant progress has been made in the development of BCI systems using various neural recording modalities, such as intracortical microelectrode arrays that record single/multi-unit activity (Taylor et al., 2002; Carmena et al., 2003; Hochberg et al., 2006, 2012; Santhanam et al., 2006; Moritz et al., 2008; Velliste et al., 2008; Ganguly and Carmena, 2009; Pohlmeyer et al., 2009; Ethier et al., 2012; 
Collinger et al., 2013a; Wodlinger et al., 2015), brain surface electrodes or electrocorticography (ECoG; Leuthardt et al., 2004; Schalk et al., 2008; Acharya et al., 2010; Chao et al., 2010; Miller et al., 2010; Moran, 2010; Schalk and Leuthardt, 2011; Yanagisawa et al., 2012; Rouse et al., 2013; Wang et al., 2013), electroencephalography (EEG; Wolpaw and McFarland, 2004; Daly and Wolpaw, 2008; Bradberry et al., 2010; McFarland et al., 2010; Doud et al., 2011; Foldes and Taylor, 2011; Ramos-Murguialday et al., 2013), and magnetoencephalography (MEG; Mellinger et al., 2007; Buch et al., 2008; Waldert et al., 2008; Wang et al., 2010b; Sudre et al., 2011; Boe et al., 2014; Florin et al., 2014).

The central component of a BCI system is its neural decoder, a set of decoding weights that transform or map brain activity to behavior of an external device, e.g., robotic arm movement (Figure 1). Establishment of an effective BCI mapping relies on two synergistic processes (Figure 1). The first is decoder calibration, where decoding weights are calculated based on brain activity and corresponding external device behavior data. The second process is BCI learning, where a BCI user learns the relationship between brain activity and resulting external device behavior given specific decoding weights. In another word, the user learns to generate specific cortical activity patterns for controlling external devices with the given decoding weights.

Researchers have developed many advanced signal processing and neural decoding algorithms for the decoder calibration process (Brockwell et al., 2004; Blankertz et al., 2006; Müller et al., 2008; Yu et al., 2009). In contrast, the BCI learning process is much less understood. To address this knowledge gap, this article will focus on BCI learning with two goals. First, in agreement with recent studies (Yin et al., 2009; Koralek et al., 2012; Rouse et al., 2013; Wander et al., 2013; Sadtler et al., 2014), we contend that BCI learning is analogous to motor and cognitive skill learning and that theories and practice developed for skill learning should inform research in BCI learning. Second, we review approaches that can promote $\mathrm{BCI}$ learning, particularly in the context of restoring volitional arm movement or controlling movement of external devices, such as computer cursors and robotic arms. BCI learning is a broad topic and it will be challenging to cover all aspects of BCI learning with reasonable depth in this review article. Hence, this review article focuses

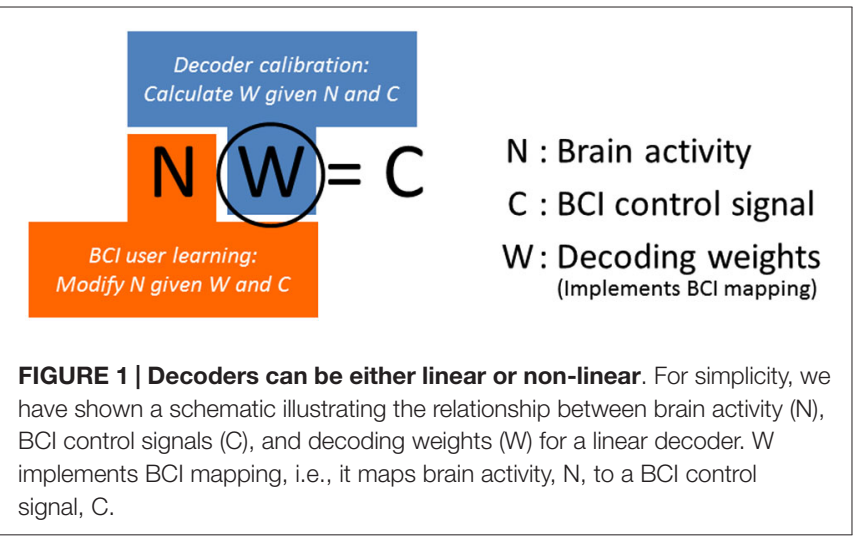

on BCI systems that use implantable electrodes, such as ECoG and intracortical microelectrode arrays, with the goal of restoring motor function.

\section{Types of BCl Mapping}

This section discusses BCI mapping in relation to the concept of "mapping" in the field of human-computer interfaces (HCI). BCI systems can be considered as a type of HCI, and BCI research should benefit from established HCI theoretical frameworks. Specifically, the term "mapping" has been widely used in HCI. Norman, a pioneer in HCI research (Norman, 1988), defined mapping as the relationship between human input (e.g., a computer mouse movement) and the resulting behavior of the system under control (e.g., a computer). Analogously, we define BCI mapping as the relationship between brain activity and the resulting behavior of an external device, such as movement of a computer cursor or a robotic arm. BCI mapping can be classified into two main types: biomimetic and artificial. The biomimetic mapping-based BCIs use decoders that aim to capture the natural relationship between cortical activity and volitional arm or hand movement which is then used to control a prosthetic arm, orthosis, or functional electrical stimulator (Georgopoulos et al., 1986; Salinas and Abbott, 1994; Moran and Schwartz, 1999; Brockwell et al., 2004; Paninski et al., 2004; Heldman et al., 2006; Schalk et al., 2007; Wang et al., 2007, 2010a; Shimoda et al., 2012; Chen et al., 2013). This type of mapping potentially provides an intuitive control scheme without undue cognitive load, especially during the initial phase of BCI learning (Wessberg and Nicolelis, 2004). Biomimetic mapping was used to achieve cortical control of high-performance prosthetic limbs using single/multi-unit activities recorded with intracortical microelectrode arrays in individuals with paralysis (Hochberg et al., 2012; Collinger et al., 2013a; Wodlinger et al., 2015).

Artificial mapping does not follow the natural relationship between cortical activity and arm/hand movement. Rather, this method either remaps cortical activity into a different movement of a device, or maps cortical activity to device movement using arbitrary decoding weights (Fetz, 2007; Moritz et al., 2008; Schalk et al., 2008; Ganguly and Carmena, 2009; McFarland et al., 2010; Wang et al., 2013). A BCI user has to learn this novel mapping in order to control an external device with his brain activity. For example, Wang et al. remapped cortical activity associated with thumb and elbow movements to two-dimensional (2D) movements of a computer cursor (Figure 2; Wang et al., 2013). During BCI training, the participant was told to associate four flexion/extension movement patterns with four cursor movement directions in $x-y$ planes. Attempted movements of thumb, elbow, both thumb and elbow, and no thumb or elbow (rest) were associated with for left, right, up and down, respectively. It is also worth noting that this approach allowed the participant to move the cursor in any directions in the 2D workspace and not just up, down, left, and right. The participant, an individual with long-term paralysis due to cervical spinal cord injury, learned this mapping and achieved cortical control of a computer cursor. 


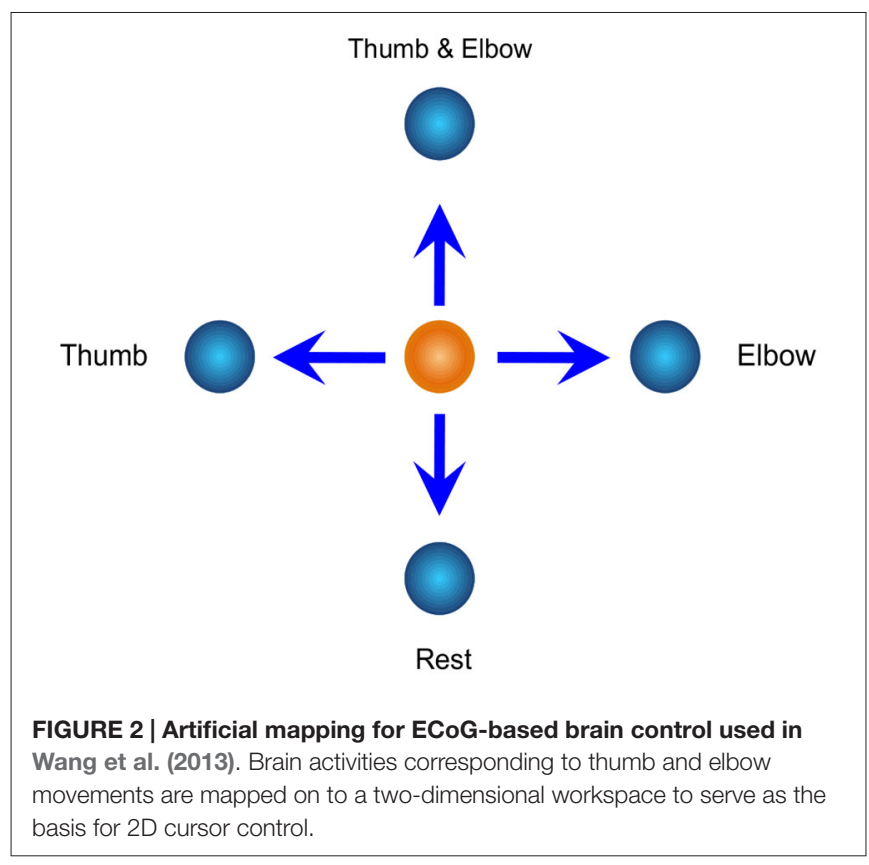

There is no strict division between biomimetic and artificial BCI mapping; rather both are parts of a continuous spectrum. Most biomimetic mapping-based studies use neural recording technologies that provide a small and potentially noisy and biased sample of the total neuronal population that controls natural limb movement. Thus, even though biomimetic mapping is intended to be intuitive, BCI users likely have to undergo a certain degree of BCI learning. Conversely, artificial mappingbased studies often build BCI learning on top of existing cortical activity patterns that naturally represent certain neuronal processes, such as those for mouth and limb movement control (Schalk et al., 2008; McFarland et al., 2010; Wang et al., 2013).

\section{Establishing the Initial BCI Mapping Using Movement-Related Paradigms}

Before any BCI learning can take place, we first need to establish the initial mapping between brain activity and intended device behavior. This is the neural decoder calibration process. While it is possible to just use a set of arbitrary or random decoding weights (Ganguly and Carmena, 2009), the typical practice is to calculate decoding weights using neural data and corresponding limb movement data. This practice is motivated by previous neurophysiology studies which have demonstrated that neurons in various cortical areas, most notably in the motor and premotor areas, fire in specific and reliable ways during the execution of volitional movements (Georgopoulos et al., 1986; Moran and Schwartz, 1999; Paninski et al., 2004; Wang et al., 2007, 2010a; Truccolo et al., 2008; Kaufman et al., 2010). A common approach for decoder calibration for individuals who are able to move their arm is the following: first, have the subject perform a series of overt movements; second, calculate decoding weights with a certain algorithm, such as the population vector algorithm (Georgopoulos et al., 1986), or the optimal linear estimator
(Salinas and Abbott, 1994), and the decoding weights capture the relationship between brain activity and natural arm movement; last, the decoding weights map brain activity to real-time control signals for external devices (Helms Tillery et al., 2003).

Clinical BCI users typically have limb paralysis or dysfunction, thus making it difficult or impossible to use overt movements for decoder calibration. One way to address this problem is to derive decoding weights using action observation paradigms based on the concept of the mirror neuron system (MNS). The MNS is a collection of neurons in the premotor and inferior parietal areas that fire both when an individual acts and when the individual observes the same action performed by another person (Buccino et al., 2004; Iacoboni and Dapretto, 2006; Rizzolatti and Sinigaglia, 2007; Fabbri-Destro and Rizzolatti, 2008). Studies in non-human primates (Tkach et al., 2007, 2008; Velliste et al., 2008) and able-bodied human subjects (Hari et al., 1998; Iacoboni and Dapretto, 2006; Perry and Bentin, 2009; Press et al., 2011; Collinger et al., 2014) suggest that primary motor cortex also demonstrates congruent activities during both action observation and action execution. Reliable motor cortical activation during action observation was also observed in individuals with chronic limb paralysis (Dushanova and Donoghue, 2010; Wang et al., 2013; Collinger et al., 2014). Therefore, action observation can be an effective approach for identifying the mapping between motor cortical activity and limb movement in absence of overt movement.

Another approach for neural decoder calibration in individuals with limb paralysis is to use motor imagery, which activates a cortical substrate similar to that of overt movement (Porro et al., 1996; Crammond, 1997; Jeannerod and Frak, 1999; McFarland et al., 2000; Jeannerod, 2001; Sharma et al., 2006). Research has demonstrated that able-bodied individuals can perform motor imagery to successfully operate BCI systems (Pfurtscheller and Neuper, 2001; Leuthardt et al., 2004; Schalk et al., 2008; Blankertz et al., 2010; Miller et al., 2010). In addition to action observation and motor imagery, simply instructing individuals with paralysis to attempt limb movement can reliably activate the motor and somatosensory cortices. BCI studies in individuals with paralysis have used this approach for both decoder calibration and brain control (Hochberg et al., 2006, 2012; Truccolo et al., 2008; Collinger et al., 2013a; Wang et al., 2013). Combination of the above techniques, such as action observation and attempted movement, will likely yield strong and reliable activation of the motor cortical areas for the initial neural decoder calibration in individuals with limb paralysis.

\section{$\mathrm{BCl}$ Learning and Motor/Cognitive Skill Learning}

BCI learning and motor/cognitive skill learning share many common characteristics, including the learning stages and neural substrates that support learning. In terms of learning stages, Fitts and colleagues suggested that motor/cognitive learning follows three stages (Fitts and Posner, 1967; VanLehn, 1996): (1) cognitive stage-an individual learns basic information about the goals and parameters of the task, i.e., learns what to do; (2) associative stage-an individual learns to convert 
their knowledge about the task into actual action, i.e., learns how to do; (3) automatic stage-an individual performs a task automatically, with minimal effort, and independent of conscious awareness (Logan, 1988). The automatic process requires little or no conscious effort, particularly in terms of working memory and attention. This process reduces mental fatigue, and enables an individual to multitask. BCI learning seems to go through similar stages. Human subjects of BCI studies have anecdotally reported transitioning from a very deliberate cognitive stage to a nearly automatic stage after practice (Curran and Stokes, 2003; Wander et al., 2013). The ability and time for a BCI user to arrive at the automatic stage will likely vary, depending on neural recording modalities, BCI mapping strategies, complexity of devices to be controlled, a user's cognitive functions, etc. Nevertheless, once learning reaches the automatic stage, a BCI user should be able to multitask, such as carry on a conversation with someone else while controlling a cursor using brain activities (Miner et al., 1998; Foldes and Taylor, 2013).

In terms of neural substrates, during BCI learning, there is significant involvement of a distributed network spanning the motor cortex, prefrontal area, parietal area, cerebellum, and striatum, all of which are also engaged during motor/cognitive skill learning (Doyon and Benali, 2005; Wander et al., 2013). Part of this network's activity decreases during BCI learning as a subject transitions from the cognitive to automatic stage (Wander et al., 2013). Furthermore, plasticity in corticostriatal circuits has been implicated in motor learning (Barnes et al., 2005; Kimchi and Laubach, 2009; Yin et al., 2009), and corticostriatal plasticity seems to be necessary for BCI learning, as well (Koralek et al., 2012). Overall, BCI learning seems to capitalize on many of the same neural circuitries involved in motor and cognitive skill learning.

Another important aspect of BCI learning to consider is "BCI illiteracy", which has been observed in EEG studies (Vidaurre and Blankertz, 2010). BCI illiteracy describes the phenomenon that certain individuals had much more difficulty in learning BCI control than others. One study reported that an estimated $15-30 \%$ of the study participants did not achieve proficient BCI control by the end of the study (Dickhaus et al., 2009). Poor BCI performance was attributed to individuals using a wrong strategy of imagining a movement instead of imaging the kinesthetic movement, and reduced modulation depth of sensorimotor rhythm during motor imagery for EEG (Blankertz et al., 2009). BCI illiteracy has not been reported by BCI studies using implantable electrodes, but the number of subjects studied is typically small (Leuthardt et al., 2004; Hochberg et al., 2012; Collinger et al., 2013a; Wang et al., 2013). Further studies are needed to better understand the underlying cause of BCI illiteracy and identify new BCI learning strategies that will alleviate BCI illiteracy.

\section{Approaches for $\mathrm{BCI}$ Learning}

During BCI learning, an individual learns to generate specific cortical activity patterns to control external devices. Similar to motor/cognitive skill learning, BCI learning produces neural adaptation in the form of functional reorganization of the cortex and changes in neuronal tuning properties (Taylor et al., 2002; Carmena et al., 2003; Neumann et al., 2004; Jarosiewicz et al., 2008; Chase et al., 2012). The duration of time required for BCI learning is associated with BCI user performance, which in turn is related to the paradigm and neural recording modality used in the study. Schalk et al. showed that five human subjects used ECoG to achieve 2D cursor control within a single session (training period of 12-36 min; Schalk et al., 2008). Wang et al. showed that a participant with tetraplegia was able to perform $3 \mathrm{D}$ cursor control using ECoG signals in 6 days of BCI training, with training sessions lasting between 4-6 h (Wang et al., 2013). Collinger et al. tested an intracortical microelectrode-based BCI system in an individual with tetraplegia (Collinger et al., 2013a). They reported that $3 \mathrm{D}$ control was achievable within a single session of BCI training and that 7D control of a robotic arm was achieved after 66 days of BCI training, with BCI training taking place three times a week and for about $3 \mathrm{~h}$ each time. Given the essential role of learning in any BCI application, it is important to survey and understand effective approaches that can promote BCI learning. These approaches can be roughly classified into five types: computer-assisted learning, co-adaptive learning, operant conditioning, sensory feedback, and cortical stimulation. These approaches are not mutually exclusive, and researchers often combine some of these approaches to facilitate BCI learning.

\section{Computer-Assisted Learning}

During the initial stage of BCI learning, researchers often use computer assist to help users learn to modulate brain signals to control external devices. The process of computerassisted learning can be discussed using two concepts from the psychology of learning. The first is the concept of "flow zone", which was introduced by Csikszentmihalyi and widely used in game design (Figure 3; Csikszentmihalyi, 1990; Dickey, 2007; Schell, 2008; Christel et al., 2013). In the flow zone, the task difficulty is balanced against a person's capability to keep the individual engaged with the learning process without stress or boredom. The second concept is "shaping", originally proposed by Skinner (Ferster and Skinner, 1957; Skinner and Ferster, 1997; Gluck et al., 2008). Shaping describes a successive approximation process during which the task goal is morphed gradually from coarse to fine, in order to help an individual refine performance and eventually perform a complex task with high precision. For example, learning how to play tennis, an individual will first learn to hit the ball across the court, and then gradually learn to control where the ball lands. The concepts of flow zone and shaping are highly connected to each other. As the task difficulty increases, the goal becomes increasingly complex and specific. By regulating task difficulty, shaping helps keep an individual in the flow zone throughout the learning process.

For BCI learning, computer assist is a powerful means to control task difficulty and keep the subject in the flow zone while shaping brain control performance. Summarizing previous studies (Taylor et al., 2002; Velliste et al., 2008; Collinger et al., 2013a,b; Rouse et al., 2013; Wang et al., 2013), computer assist is 


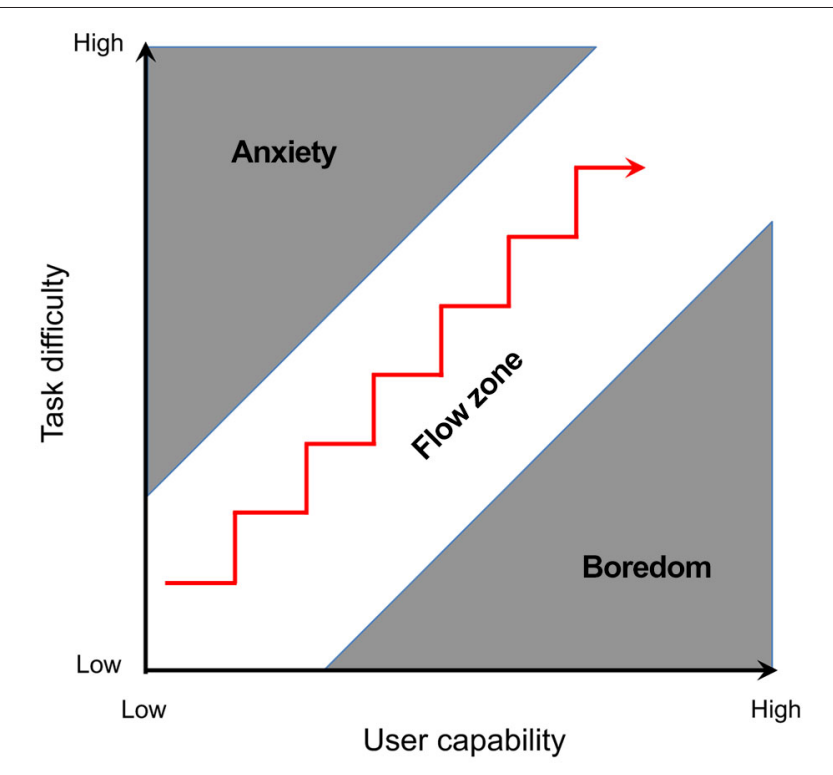

FIGURE 3 | Graph of Csikszentmihalyi's flow state when a person's ability to execute a task balances the difficulty of the task they have to perform (Figure adapted from Csikszentmihalyi, 1990).

the approach where the control signal derived from brain activity is combined with an assistive signal automatically generated by a computer to help the subject learn brain control of devices. Here we describe computer assist in the context of cursor control for convenience of discussion. Generally speaking, there are two types of computer assists: active assist and passive assist (Velliste et al., 2008; Collinger et al., 2013a; Wang et al., 2013). Active assist directly drives the cursor toward the target location, whereas passive assist only constrains the deviation of cursor movement from the ideal trajectory without actively pushing the cursor toward the target location. Helms Tillery et al. have indicated that computer-assisted $\mathrm{BCI}$ learning led to greater learning rates than BCI learning without any assist (Helms Tillery et al., 2003). Furthermore, an effective training schedule to adjust the level of computer assist and task difficulty is critical to keep the subject in the flow zone and thus promote rapid BCI learning. While such adjustments are often done empirically, Zhang et al. has proposed an adaptive algorithm to automatically adjust computer assist level based on subject performance in order to maximize the learning rate (Zhang et al., 2012). Lastly, an important factor to consider is that computer assist can mask or distort the actual effect of brain control signals and impair BCI learning. In our experience, when the amplitude of computer assist is comparable to the brain control signal the resulting cursor movement can confuse the subject and even hinder the learning process. More rigorous modeling and experimental studies are needed to better inform the field about what type of computer assist to use, when to use or adjust computer assist, and how much computer assist should be applied to maximize the learning rate.

\section{Co-Adaptive BCI Learning}

BCI learning has the potential to induce cortical plasticity, manifested as changes in both modulation depth and preferred directions of neurons used for BCI control (Taylor et al., 2002;
Jarosiewicz et al., 2008). To maximally capitalize on these cortical changes, researchers proposed the concept of "co-adaptation", which involves both periodic calibration of neural decoder and the brain adapting to the neural decoder (Taylor et al., 2002; Sanchez et al., 2009). One specific form of co-adaptive learning is the "turn-taking adaptation" method used in our previous study, where the subject and neural decoder took turns to adapt to each other (Wang et al., 2013). During the user learning period, the neural decoder remained constant for 5 blocks of 20 trials of real-time BCI operation (approximately $15 \mathrm{~min}$ ). During the decoder calibration period, the subject was instructed to behave consistently for 5 blocks of 20 trials ( $15 \mathrm{~min}$ ), i.e., use the same attempted movement scheme, to generate consistent neural data for decoder calibration. The decoder was recalibrated either daily or when the subject's performance plateaued. Another approach used by our study was "incremental learning", where each BCI session always started with the neural decoder used at the end of the previous session (Wang et al., 2013). This approach was possible given the stability of the ECoG signals. Differing from previous approaches where a new decoder was calculated at the beginning of each day's testing, the incremental learning approach enabled the subject to build upon what he learned from previous sessions (Ganguly and Carmena, 2009).

\section{Operant Conditioning}

Operant conditioning is a learning process that makes subjects associate a particular behavior with a specific consequence through reinforcements. The reinforcement is provided when a subject completes a trial successfully, and it can be juice or food rewards in animal studies, and provision of a token/award or increments in scores in human studies. In the field of BCI, operant conditioning is typically used to train experimental animals to discover the underlying BCI mapping by trial and error, without explicit instructions (Chase and Schwartz, 2011; Arduin et al., 2013). Operant conditioning of brain activity through biofeedback is a particularly useful paradigm for learning arbitrary BCI mappings (Fetz, 1969, 2007; Ganguly and Carmena, 2010; Engelhard et al., 2013). In this approach subjects learn to generate specific brain activity patterns based on realtime sensory feedback (visual, auditory, tactile, etc.) to complete a BCI task. Operant conditioning can modulate single neuron firing rates (Fetz, 1969), ensemble neuronal activity (Ganguly and Carmena, 2009), neuronal synchrony (Engelhard et al., 2013), and high gamma band power of field potential signals (Rouse et al., 2013; Wander et al., 2013). Through operant conditioning an ensemble of neurons can potentially assume a novel yet reproducible pattern of activity, allowing the subject to achieve reliable brain control of a device.

Interestingly, through operant conditioning subjects sometimes acquire brain control of an external device without being consciously aware of how they are performing the task (Kaplan et al., 2005). This is similar to implicit learning (Frensch and Rünger, 2003), which is defined as "non-episodic learning of complex information in an incidental manner, without awareness of what has been learned" (Seger, 1994). In other words, individuals learn certain skills without being aware that learning has occurred (Gluck et al., 2008). Implicit learning 
in the context of BCI learning is a scientifically intriguing and clinically relevant topic to investigate.

\section{Sensory Feedback}

Many approaches discussed so far make substantial use of sensory feedback. Feedback is an essential component of BCI learning, therefore we are devoting this section for sensory feedback. Borrowing concepts from motor learning, we will discuss two types of feedback used in BCI learning: the online feedback that provides detailed knowledge of performance (KP) and the offline feedback that provides the knowledge of results (KR), i.e., success or failure with respect to the goal (Schmidt, 2008). Both KP and KR feedbacks are crucial for effective BCI learning. KP feedback provides continuous or frequent feedback to help the participant complete individual trials. For example, in a typical cursor control task, KP feedback is provided to a user visually as movement of the cursor under brain control. KR feedback is provided at the end of a trial or a session, often through either auditory tones indicating success or failure of a trial or simply feedback about success rates.

Feedback can also be categorized based on the sensory modality it uses, such as visual, auditory, and somatosensory feedback. Research has demonstrated that visual feedback plays a key role in skill learning (Hinterberger et al., 2004; Abbott, 2006; Leeb et al., 2006; Blankertz et al., 2008; Barbero and GrosseWentrup, 2010). In addition to visual feedback, the BCI field has seen a significant increase in the use of somatosensory feedback to further improve BCI performance. Loss of somatosensory feedback significantly impairs motor performance, particularly for grasping and object manipulation (Macefield et al., 1996; Monzée et al., 2003; Goodwin and Wheat, 2004; Bensmaia and Miller, 2014). Lack of somatosensory information may also result in poor motor planning (Brochier et al., 1999). Thus, it is critical for a BCI system to have the capability to provide somatosensory feedback, especially for brain control of prosthetic arms. A number of BCI studies have demonstrated that electrical stimulation of the peripheral nerve, dorsal root ganglia, or the somatosensory cortex can elicit artificial sensation that the subjects can use to perform sensory discrimination tasks or even closed-loop brain-control tasks successfully (Romo et al., 2000; Horch et al., 2011; Miller and Weber, 2011; O’Doherty et al., 2011; Weber et al., 2011, 2012; Johnson et al., 2013; Tabot et al., 2013; Zaaimi et al., 2013; Bensmaia and Miller, 2014).

\section{Cortical Stimulation}

Since cortical stimulation can modulate cortical activity patterns (Hummel and Cohen, 2006; Harvey and Nudo, 2007), it is conceivable that cortical stimulation may be able to replace or supplement repetitive behavior training to induce changes in cortical activity and accelerate BCI learning (Soekadar et al., 2014). While this approach has not been well investigated for BCI learning, previous studies about neuroplasticity (Gage et al., 2005; Jackson et al., 2006) and rehabilitation using neurostimulation (Ziemann et al., 2002; Hummel et al., 2005; Hummel and Cohen, 2006; Harvey and Nudo, 2007; Perez and Cohen, 2009; Plow et al., 2009; Reis et al., 2009) can shed some light on the feasibility of this approach. At the macroscopic level, cortical areas can be stimulated non-invasively using transcranial magnetic or current stimulations. In the context of stroke rehabilitation, it has been suggested that such stimulation can enhance motor cortical excitability and change cortical connectivity (Hummel et al., 2005; Hummel and Cohen, 2006; Perez and Cohen, 2009). At the microscopic level, based on the concept of Hebbian or associative learning, motor cortical reorganization can be induced by coupling action potentials of one motor cortical neuron with electrical stimulation impulses of another motor cortical neuron (Jackson et al., 2006; Stevenson et al., 2012). A recent pilot study has shown that transcranial direct current stimulation induces eventrelated desynchronization associated with sensorimotor rhythm (Wei et al., 2013). This event-related desynchronization, along with motor imagery, was used to improve the performance of an EEG based BCI. Besides electromagnetic stimulation, optogenetics is another approach to stimulate cortical tissue. This technique uses light to activate neurons that have been genetically modified to have light-sensitive ion channels. Optogenetics has enabled manipulation of neuronal activity with much higher spatial and temporal precisions than was previously possible (Tye and Deisseroth, 2012). Lima and Miesenbock demonstrated reliable control of neuronal spiking in the millisecond-timescale and control of excitatory and inhibitory synaptic transmission (Lima and Miesenböck, 2005). Optogenetics is currently limited to animal research as it requires genetic manipulation (Chow and Boyden, 2013), but this technique has great potential for facilitating learning by inducing repeatable patterns of neural activity.

Given all these possibilities of directly modulating cortical activity and connectivity, we believe that cortical stimulation can be a powerful approach to promote BCI learning. Cortical stimulation may not only be able to modify general cortical excitability at a macroscopic level, but also directly entrain cortical activity into specific spatiotemporal patterns for effective brain control of external devices.

\section{Conclusion}

In this article, we provided an overview of BCI learning by discussing BCI mapping, relationship between BCI learning and motor/cognitive skill learning, and approaches for accelerating BCI learning. We believe that advancement in theories and practice of BCI learning, coupled with development of clinically reliable neural interfaces, will ultimately benefit many individuals with disabilities and our society.

\section{Acknowledgments}

This work was supported by the University of Pittsburgh Medical Center (UPMC), UPMC Rehabilitation Institute, the National Institutes of Health (NIH) (Grants 3R01NS05025605S1 and 8KL2TR000146), and SPAWAR (Contract N66001-10-C-4056 20100630). This material is supported in part by the Office of Research and Development, Rehabilitation Research and Development Service, VA Center of Excellence in Wheelchairs and Associated Rehab Engineering, Grant\# 
B6789C. The contents of this publication do not represent the views of the Department of Veterans Affairs or the United States

\section{References}

Abbott, A. (2006). Neuroprosthetics: in search of the sixth sense. Nature 442, 125-127. doi: 10.1038/442125a

Acharya, S., Fifer, M. S., Benz, H. L., Crone, N. E., and Thakor, N. V. (2010). Electrocorticographic amplitude predicts finger positions during slow grasping motions of the hand. J. Neural Eng. 7:046002. doi: 10.1088/17412560/7/4/046002

Arduin, P. J., Frégnac, Y., Shulz, D. E., and Ego-Stengel, V. (2013). "Master" neurons induced by operant conditioning in rat motor cortex during a brainmachine interface task. J. Neurosci. 33, 8308-8320. doi: 10.1523/JNEUROSCI. 2744-12.2013

Barbero, A., and Grosse-Wentrup, M. (2010). Biased feedback in brain-computer interfaces. J. Neuroeng. Rehabil. 7:34. doi: 10.1186/1743-0003-7-34

Barnes, T. D., Kubota, Y., Hu, D., Jin, D. Z., and Graybiel, A. M. (2005). Activity of striatal neurons reflects dynamic encoding and recoding of procedural memories. Nature 437, 1158-1161. doi: 10.1038/nature04053

Bensmaia, S. J., and Miller, L. E. (2014). Restoring sensorimotor function through intracortical interfaces: progress and looming challenges. Nat. Rev. Neurosci. 15, 313-325. doi: 10.1038/nrn3724

Blankertz, B., Dornhege, G., Lemm, S., Krauledat, M., Curio, G., and Muller, K. R. (2006). The Berlin brain-computer interface: machine learning based detection of user specific brain states. J. Univers. Comput. Sci. 12, 581-607. doi: 10.3217/ jucs-012-06-0581

Blankertz, B., Sanelli, C., Halder, S., Hammer, E.-M., Kübler, A., Müller, K. R., Curio, G., et al. (2009). "Predicting BCI performance to study BCI illiteracy," in 7th International Symposium on Noninvasive Functional Source Imaging of the Brain and Heart and International Conference on Bioelectromagnetism (Rome, Italy: Sapienza University of Rome).

Blankertz, B., Sannelli, C., Halder, S., Hammer, E. M., Kübler, A., Müller, K. R., et al. (2010). Neurophysiological predictor of SMR-based BCI performance. Neuroimage 51, 1303-1309. doi: 10.1016/j.neuroimage.2010.03.022

Blankertz, B., Tomioka, R., Lemm, S., Kawanabe, M., and Muller, K. R. (2008). Optimizing spatial filters for robust EEG single-trial analysis. IEEE Signal Proc. Mag. 25, 41-56. doi: 10.1109/msp.2008.4408441

Boe, S., Gionfriddo, A., Kraeutner, S., Tremblay, A., Little, G., and Bardouille, T. (2014). Laterality of brain activity during motor imagery is modulated by the provision of source level neurofeedback. Neuroimage 101, 159-167. doi: 10. 1016/j.neuroimage.2014.06.066

Bradberry, T. J., Gentili, R. J., and Contreras-Vidal, J. L. (2010). Reconstructing three-dimensional hand movements from noninvasive electroencephalographic signals. J. Neurosci. 30, 3432-3437. doi: 10. 1523/JNEUROSCI.6107-09.2010

Brochier, T., Boudreau, M. J., Paré, M., and Smith, A. M. (1999). The effects of muscimol inactivation of small regions of motor and somatosensory cortex on independent finger movements and force control in the precision grip. Exp. Brain Res. 128, 31-40. doi: 10.1007/s002210050814

Brockwell, A. E., Rojas, A. L., and Kass, R. E. (2004). Recursive bayesian decoding of motor cortical signals by particle filtering. J. Neurophysiol. 91, 1899-1907. doi: 10.1152/jn.00438.2003

Buccino, G., Vogt, S., Ritzl, A., Fink, G. R., Zilles, K., Freund, H. J., et al. (2004). Neural circuits underlying imitation learning of hand actions: an event-related fMRI study. Neuron 42, 323-334. doi: 10.1016/s0896-6273(04)00181-3

Buch, E., Weber, C., Cohen, L. G., Braun, C., Dimyan, M. A., Ard, T., et al. (2008). Think to move: a neuromagnetic brain-computer interface (BCI) system for chronic stroke. Stroke 39, 910-917. doi: 10.1161/STROKEAHA.107.505313

Carmena, J. M., Lebedev, M. A., Crist, R. E., O’Doherty, J. E., Santucci, D. M., Dimitrov, D. F., et al. (2003). Learning to control a brain-machine interface for reaching and grasping by primates. PLoS Biol. 1:E42. doi: 10.1371/journal.pbio. 0000042

Chao, Z. C., Nagasaka, Y., and Fujii, N. (2010). Long-term asynchronous decoding of arm motion using electrocorticographic signals in monkeys. Front. Neuroeng. 3:3. doi: 10.3389/fneng.2010.00003
Government. The funders had no role in preparation of this review article.

Chase, S. M., Kass, R. E., and Schwartz, A. B. (2012). Behavioral and neural correlates of visuomotor adaptation observed through a brain-computer interface in primary motor cortex. J. Neurophysiol. 108, 624-644. doi: 10. 1152/jn.00371.2011

Chase, S. M., and Schwartz, A. B. (2011). Inference from populations: going beyond models. Prog. Brain Res. 192, 103-112. doi: 10.1016/B978-0-444-533555.00007-5

Chen, C., Shin, D., Watanabe, H., Nakanishi, Y., Kambara, H., Yoshimura, N., et al. (2013). Prediction of hand trajectory from electrocorticography signals in primary motor cortex. PLoS One 8:e83534. doi: 10.1371/journal.pone.00 83534

Chow, B. Y., and Boyden, E. S. (2013). Optogenetics and translational medicine. Sci. Transl. Med. 5:177ps175. doi: 10.1126/scitranslmed.3003101

Christel, M. G., Stevens, S., Champer, M., Balash, J., Brice, S., Maher, B., et al. (2013). Beanstalk: A Unity Game Addressing Balance Principles, SocioEmotional Learning and Scientific Inquiry. Vancouver, BC: Games Innovation Conference (IGIC), 36-39.

Collinger, J. L., Kryger, M. A., Barbara, R., Betler, T., Bowsher, K., Brown, E. H., et al. (2013b). Collaborative approach in the development of high-performance brain-computer interfaces for a neuroprosthetic arm: translation from animal models to human control. Clin. Transl. Sci. 7, 52-59. doi: 10.1111/cts.12086

Collinger, J. L., Vinjamuri, R., Degenhart, A. D., Weber, D. J., Sudre, G. P., Boninger, M. L., et al. (2014). Motor-related brain activity during action observation: a neural substrate for electrocorticographic brain-computer interfaces after spinal cord injury. Front. Integr. Neurosci. 8:17. doi: 10. 3389/fnint.2014.00017

Collinger, J. L., Wodlinger, B., Downey, J. E., Wang, W., Tyler-Kabara, E. C., Weber, D. J., et al. (2013a). High-performance neuroprosthetic control by an individual with tetraplegia. Lancet 381, 557-564. doi: 10.1016/S01406736(12)61816-9

Crammond, D. J. (1997). Motor imagery: never in your wildest dream. Trends Neurosci. 20, 54-57. doi: 10.1016/s0166-2236(96)30019-2

Csikszentmihalyi, M. (1990). Flow: The Psychology of Optimal Experience. New York: Harper and Row.

Curran, E. A., and Stokes, M. J. (2003). Learning to control brain activity: a review of the production and control of EEG components for driving brain-computer interface (BCI) systems. Brain Cogn. 51, 326-336. doi: 10. 1016/s0278-2626(03)00036-8

Daly, J. J., and Wolpaw, J. R. (2008). Brain-computer interfaces in neurological rehabilitation. Lancet Neurol. 7, 1032-1043. doi: 10.1016/S14744422(08)70223-0

Dickey, M. D. (2007). Game design and learning: a conjectural analysis of how massively multiple online role-playing games (MMORPGs) foster intrinsic motivation. Educ. Technol. Res. Dev. 55, 253-273. doi: 10.1007/s11423-006 9004-7

Dickhaus, T., Sannelli, C., Müller, K. R., Curio, G., and Blankertz, B. (2009) Predicting BCI performance to study BCI illiteracy. BMC Neurosci. 10:P84. doi: 10.1186/1471-2202-10-s1-p84

Donoghue, J. P. (2008). Bridging the brain to the world: a perspective on neural interface systems. Neuron 60, 511-521. doi: 10.1016/j.neuron.2008.10.037

Doud, A. J., Lucas, J. P., Pisansky, M. T., and He, B. (2011). Continuous threedimensional control of a virtual helicopter using a motor imagery based braincomputer interface. PLoS One 6:e26322. doi: 10.1371/journal.pone.0026322

Doyon, J., and Benali, H. (2005). Reorganization and plasticity in the adult brain during learning of motor skills. Curr. Opin. Neurobiol. 15, 161-167. doi: 10. 1109/ijcnn.2005.1556102

Dushanova, J., and Donoghue, J. (2010). Neurons in primary motor cortex engaged during action observation. Eur. J. Neurosci. 31, 386-398. doi: 10.1111/j. 1460-9568.2009.07067.x

Engelhard, B., Ozeri, N., Israel, Z., Bergman, H., and Vaadia, E. (2013). Inducing gamma oscillations and precise spike synchrony by operant conditioning via brain-machine interface. Neuron 77, 361-375. doi: 10.1016/j.neuron.2012. 11.015 
Ethier, C., Oby, E. R., Bauman, M. J., and Miller, L. E. (2012). Restoration of grasp following paralysis through brain-controlled stimulation of muscles. Nature 485, 368-371. doi: 10.1038/nature 10987

Fabbri-Destro, M., and Rizzolatti, G. (2008). Mirror neurons and mirror systems in monkeys and humans. Physiology (Bethesda) 23, 171-179. doi: 10 . 1152/physiol.00004.2008

Ferster, C. B., and Skinner, B. F. (1957). Schedules of Reinforcement. East Norwalk, CT: Appleton-Century-Crofts.

Fetz, E. E. (1969). Operant conditioning of cortical unit activity. Science 163, 955-958. doi: 10.1126/science.163.3870.955

Fetz, E. E. (2007). Volitional control of neural activity: implications for braincomputer interfaces. J. Physiol. 579, 571-579. doi: 10.1113/jphysiol.2006. 127142

Fitts, P. M., and Posner, M. I. (1967). Human Performance. Belmont Calif.: Brooks/Cole Pub. Co..

Florin, E., Bock, E., and Baillet, S. (2014). Targeted reinforcement of neural oscillatory activity with real-time neuroimaging feedback. Neuroimage 88, 54-60. doi: 10.1016/j.neuroimage.2013.10.028

Foldes, S. T., and Taylor, D. M. (2011). Offline comparison of spatial filters for two-dimensional movement control with noninvasive field potentials. J. Neural Eng. 8:046022. doi: 10.1088/1741-2560/8/4/046022

Foldes, S. T., and Taylor, D. M. (2013). Speaking and cognitive distractions during EEG-based brain control of a virtual neuroprosthesis-arm. J. Neuroeng. Rehabil. 10:116. doi: 10.1186/1743-0003-10-116

Frensch, P. A., and Rünger, D. (2003). Implicit learning. Curr. Direct. Psycholo. Sci. 12, 13-18. doi: 10.1111/1467-8721.01213

Gage, G. J., Ludwig, K. A., Otto, K. J., Ionides, E. L., and Kipke, D. R. (2005). Naive coadaptive cortical control. J. Neural Eng. 2, 52-63. doi: 10.1088/17412560/2/2/006

Ganguly, K., and Carmena, J. M. (2009). Emergence of a stable cortical map for neuroprosthetic control. PLoS Biol. 7:e1000153. doi: 10.1371/journal.pbio. 1000153

Ganguly, K., and Carmena, J. M. (2010). Neural correlates of skill acquisition with a cortical brain-machine interface. J. Mot. Behav. 42, 355-360. doi: 10. 1080/00222895.2010.526457

Georgopoulos, A. P., Schwartz, A. B., and Kettner, R. E. (1986). Neuronal population coding of movement direction. Science 233, 1416-1419. doi: 10. $1126 /$ science. 3749885

Gluck, M. A., Mercado, E., and Myers, C. E. (2008). Learning and Memory: From Brain to Behavior. New York: Worth Publishers.

Goodwin, A. W., and Wheat, H. E. (2004). Sensory signals in neural populations underlying tactile perception and manipulation. Annu. Rev. Neurosci. 27, 53-77. doi: 10.1146/annurev.neuro.26.041002.131032

Hari, R., Forss, N., Avikainen, S., Kirveskari, E., Salenius, S., and Rizzolatti, G. (1998). Activation of human primary motor cortex during action observation: a neuromagnetic study. Proc. Natl. Acad. Sci. U S A 95, 15061-15065. doi: 10. 1073/pnas.95.25.15061

Harvey, R. L., and Nudo, R. J. (2007). Cortical brain stimulation: a potential therapeutic agent for upper limb motor recovery following stroke. Top. Stroke Rehabil. 14, 54-67. doi: 10.1310/tsr1406-54

Heldman, D. A., Wang, W., Chan, S. S., and Moran, D. W. (2006). Local field potential spectral tuning in motor cortex during reaching. IEEE Trans. Neural Syst. Rehabil. Eng. 14, 180-183. doi: 10.1109/tnsre.2006.875549

Helms Tillery, S. I., Taylor, D. M., and Schwartz, A. B. (2003). Training in cortical control of neuroprosthetic devices improves signal extraction from small neuronal ensembles. Rev. Neurosci. 14, 107-119. doi: 10.1515/revneuro. 2003.14.1-2.107

Hinterberger, T., Neumann, N., Pham, M., Kübler, A., Grether, A., Hofmayer, N., et al. (2004). A multimodal brain-based feedback and communication system. Exp. Brain Res. 154, 521-526. doi: 10.1007/s00221-003-1690-3

Hochberg, L. R., Bacher, D., Jarosiewicz, B., Masse, N. Y., Simeral, J. D., Vogel, J., et al. (2012). Reach and grasp by people with tetraplegia using a neurally controlled robotic arm. Nature 485, 372-375. doi: 10.1038/nature11076

Hochberg, L. R., Serruya, M. D., Friehs, G. M., Mukand, J. A., Saleh, M., Caplan, A. H., et al. (2006). Neuronal ensemble control of prosthetic devices by a human with tetraplegia. Nature 442, 164-171. doi: 10.1038/nature04970

Horch, K., Meek, S., Taylor, T. G., and Hutchinson, D. T. (2011). Object discrimination with an artificial hand using electrical stimulation of peripheral tactile and proprioceptive pathways with intrafascicular electrodes. IEEE Trans. Neural Syst. Rehabil. Eng. 19, 483-489. doi: 10.1109/TNSRE.2011.2162635

Hummel, F., Celnik, P., Giraux, P., Floel, A., Wu, W. H., Gerloff, C., et al. (2005). Effects of non-invasive cortical stimulation on skilled motor function in chronic stroke. Brain 128, 490-499. doi: 10.1093/brain/awh369

Hummel, F. C., and Cohen, L. G. (2006). Non-invasive brain stimulation: a new strategy to improve neurorehabilitation after stroke? Lancet Neurol. 5, 708-712. doi: 10.1016/s1474-4422(06)70525-7

Iacoboni, M., and Dapretto, M. (2006). The mirror neuron system and the consequences of its dysfunction. Nat. Rev. Neurosci. 7, 942-951. doi: 10 $1038 /$ nrn2024

Jackson, A., Mavoori, J., and Fetz, E. E. (2006). Long-term motor cortex plasticity induced by an electronic neural implant. Nature 444, 56-60. doi: 10 . 1038/nature05226

Jarosiewicz, B., Chase, S. M., Fraser, G. W., Velliste, M., Kass, R. E., and Schwartz, A. B. (2008). Functional network reorganization during learning in a braincomputer interface paradigm. Proc. Natl. Acad. Sci. U S A 105, 19486-19491. doi: 10.1073/pnas.0808113105

Jeannerod, M. (2001). Neural simulation of action: a unifying mechanism for motor cognition. Neuroimage 14, S103-S109. doi: 10.1006/nimg.2001.0832

Jeannerod, M., and Frak, V. (1999). Mental imaging of motor activity in humans. Curr. Opin. Neurobiol. 9, 735-739. doi: 10.1016/s0959-4388(99)00038-0

Johnson, L. A., Wander, J. D., Sarma, D., Su, D. K., Fetz, E. E., and Ojemann, J. G. (2013). Direct electrical stimulation of the somatosensory cortex in humans using electrocorticography electrodes: a qualitative and quantitative report. J. Neural Eng. 10:036021. doi: 10.1088/1741-2560/10/3/036021

Kaplan, A. Y., Lim, J. J., Jin, K. S., Park, B. W., Byeon, J. G., and Tarasova, S. U. (2005). Unconscious operant conditioning in the paradigm of brain-computer interface based on color perception. Int. J. Neurosci. 115, 781-802. doi: 10. 1080/00207450590881975

Kaufman, M. T., Churchland, M. M., Santhanam, G., Yu, B. M., Afshar, A., Ryu, S. I., et al. (2010). Roles of monkey premotor neuron classes in movement preparation and execution. J. Neurophysiol. 104, 799-810. doi: 10.1152/jn. 00231.2009

Kimchi, E. Y., and Laubach, M. (2009). Dynamic encoding of action selection by the medial striatum. J. Neurosci. 29, 3148-3159. doi: 10.1523/JNEUROSCI. 5206-08.2009

Koralek, A. C., Jin, X., Long, J. D. 2nd, Costa, R. M., and Carmena, J. M. (2012). Corticostriatal plasticity is necessary for learning intentional neuroprosthetic skills. Nature 483, 331-335. doi: 10.1038/nature10845

Leeb, R., Keinrath, C., Friedman, D., Guger, C., Scherer, R., Neuper, C., et al. (2006). Walking by thinking: the brainwaves are crucial, not the muscles! Presence Teleop. Virt. Environ. 15, 500-514. doi: 10.1162/pres.15.5.500

Leuthardt, E. C., Schalk, G., Wolpaw, J. R., Ojemann, J. G., and Moran, D. W. (2004). A brain-computer interface using electrocorticographic signals in humans. J. Neural Eng. 1, 63-71. doi: 10.1088/1741-2560/1/2/001

Lima, S. Q., and Miesenböck, G. (2005). Remote control of behavior through genetically targeted photostimulation of neurons. Cell 121, 141-152. doi: 10 . 1016/j.cell.2005.02.004

Logan, G. D. (1988). Toward an instance theory of automatization. Psychol. Rev. 95, 492-527. doi: 10.1037/0033-295x.95.4.492

Macefield, V. G., Häger-Ross, C., and Johansson, R. S. (1996). Control of grip force during restraint of an object held between finger and thumb: responses of cutaneous afferents from the digits. Exp. Brain Res. 108, 155-171. doi: 10. 1007/bf00242913

McFarland, D. J., Miner, L. A., Vaughan, T. M., and Wolpaw, J. R. (2000). Mu and beta rhythm topographies during motor imagery and actual movements. Brain Topogr. 12, 177-186. doi: 10.1023/A:1023437823106

McFarland, D. J., Sarnacki, W. A., and Wolpaw, J. R. (2010). Electroencephalographic (EEG) control of three-dimensional movement. J. Neural Eng. 7:036007. doi: 10.1088/1741-2560/7/3/036007

Mellinger, J., Schalk, G., Braun, C., Preissl, H., Rosenstiel, W., Birbaumer, N., et al. (2007). An MEG-based brain-computer interface (BCI). Neuroimage 36, 581-593. doi: 10.1016/j.neuroimage.2007.03.019

Miller, K. J., Schalk, G., Fetz, E. E., den Nijs, M., Ojemann, J. G., and Rao, R. P. (2010). Cortical activity during motor execution, motor imagery and imagerybased online feedback. Proc. Natl. Acad. Sci. U S A 107, 4430-4435. doi: 10. 1073/pnas.0913697107 
Miller, L. E., and Weber, D. J. (2011). Brain training: cortical plasticity and afferent feedback in brain-machine interface systems. IEEE Trans. Neural Syst. Rehabil. Eng. 19, 465-467. doi: 10.1109/TNSRE.2011.2168989

Miner, L. A., McFarland, D. J., and Wolpaw, J. R. (1998). Answering questions with an electroencephalogram-based brain-computer interface. Arch. Phys. Med. Rehabil. 79, 1029-1033. doi: 10.1016/s0003-9993(98) 90165-4

Monzée, J., Lamarre, Y., and Smith, A. M. (2003). The effects of digital anesthesia on force control using a precision grip. J. Neurophysiol. 89, 672-683. doi: 10. $1152 /$ jn. 00434.2001

Moran, D. (2010). Evolution of brain-computer interface: action potentials, local field potentials and electrocorticograms. Curr. Opin. Neurobiol. 20, 741-745. doi: $10.1016 /$ j.conb.2010.09.010

Moran, D. W., and Schwartz, A. B. (1999). Motor cortical representation of speed and direction during reaching. J. Neurophysiol. 82, 2676-2692.

Moritz, C. T., Perlmutter, S. I., and Fetz, E. E. (2008). Direct control of paralysed muscles by cortical neurons. Nature 456, 639-642. doi: 10.1038/nature 07418

Müller, K. R., Tangermann, M., Dornhege, G., Krauledat, M., Curio, G., and Blankertz, B. (2008). Machine learning for real-time single-trial EEG-analysis: from brain-computer interfacing to mental state monitoring. J. Neurosci. Methods 167, 82-90. doi: 10.1016/j.jneumeth.2007.09.022

Neumann, N., Hinterberger, T., Kaiser, J., Leins, U., Birbaumer, N., and Kübler, A. (2004). Automatic processing of self-regulation of slow cortical potentials: evidence from brain-computer communication in paralysed patients. Clin. Neurophysiol. 115, 628-635. doi: 10.1016/j.clinph.2003.10.030

Norman, D. A. (1988). The Psychology of Everyday Things. New York: Basic Books.

O’Doherty, J. E., Lebedev, M. A., Ifft, P. J., Zhuang, K. Z., Shokur, S., Bleuler, H., et al. (2011). Active tactile exploration using a brain-machine-brain interface. Nature 479, 228-231. doi: 10.1038/nature10489

Paninski, L., Fellows, M. R., Hatsopoulos, N. G., and Donoghue, J. P. (2004). Spatiotemporal tuning of motor cortical neurons for hand position and velocity. J. Neurophysiol. 91, 515-532. doi: 10.1152/jn.00587.2002

Perez, M. A., and Cohen, L. G. (2009). Interhemispheric inhibition between primary motor cortices: what have we learned? J. Physiol. 587, 725-726. doi: 10. 1113/jphysiol.2008.166926

Perry, A., and Bentin, S. (2009). Mirror activity in the human brain while observing hand movements: a comparison between EEG desynchronization in the murange and previous fMRI results. Brain Res. 1282, 126-132. doi: 10.1016/j. brainres.2009.05.059

Pfurtscheller, G., and Neuper, C. (2001). Motor imagery and direct braincomputer communication. Proc. IEEE 89, 1123-1134. doi: 10.1109/5.939829

Plow, E. B., Carey, J. R., Nudo, R. J., and Pascual-Leone, A. (2009). Invasive cortical stimulation to promote recovery of function after stroke a critical appraisal. Stroke 40, 1926-1931. doi: 10.1161/STROKEAHA.108.540823

Pohlmeyer, E. A., Oby, E. R., Perreault, E. J., Solla, S. A., Kilgore, K. L., Kirsch, R. F., et al. (2009). Toward the restoration of hand use to a paralyzed monkey: brain-controlled functional electrical stimulation of forearm muscles. PLoS One 4:e5924. doi: 10.1371/journal.pone.0005924

Porro, C. A., Francescato, M. P., Cettolo, V., Diamond, M. E., Baraldi, P., Zuiani, C., et al. (1996). Primary motor and sensory cortex activation during motor performance and motor imagery: a functional magnetic resonance imaging study. J. Neurosci. 16, 7688-7698.

Press, C., Cook, J., Blakemore, S. J., and Kilner, J. (2011). Dynamic modulation of human motor activity when observing actions. J. Neurosci. 31, 2792-2800. doi: 10.1523/JNEUROSCI.1595-10.2011

Ramos-Murguialday, A., Broetz, D., Rea, M., Läer, L., Yilmaz, O., Brasil, F. L., et al. (2013). Brain-machine interface in chronic stroke rehabilitation: a controlled study. Ann. Neurol. 74, 100-108. doi: 10.1002/ana.23879

Reis, J., Schambra, H. M., Cohen, L. G., Buch, E. R., Fritsch, B., Zarahn, E., et al. (2009). Noninvasive cortical stimulation enhances motor skill acquisition over multiple days through an effect on consolidation. Proc. Natl. Acad. Sci. U S A 106, 1590-1595. doi: 10.1073/pnas.0805413106

Rizzolatti, G., and Sinigaglia, C. (2007). Mirror neurons and motor intentionality. Funct. Neurol. 22, 205-210.

Romo, R., Hernández, A., Zainos, A., Brody, C. D., and Lemus, L. (2000). Sensing without touching: psychophysical performance based on cortical microstimulation. Neuron 26, 273-278. doi: 10.1016/s0896-6273(00)81156-3
Rouse, A. G., Williams, J. J., Wheeler, J. J., and Moran, D. W. (2013). Cortical adaptation to a chronic micro-electrocorticographic brain computer interface. J. Neurosci. 33, 1326-1330. doi: 10.1523/JNEUROSCI.0271-12.2013

Sadtler, P. T., Quick, K. M., Golub, M. D., Chase, S. M., Ryu, S. I., Tyler-Kabara, E. C., et al. (2014). Neural constraints on learning. Nature 512, 423-426. doi: 10. 1038/nature 13665

Salinas, E., and Abbott, L. F. (1994). Vector reconstruction from firing rates. J. Comput. Neurosci. 1, 89-107. doi: 10.1007/bf00962720

Sanchez, J. C., Mahmoudi, B., DiGiovanna, J., and Principe, J. C. (2009). Exploiting co-adaptation for the design of symbiotic neuroprosthetic assistants. Neural Netw. 22, 305-315. doi: 10.1016/j.neunet.2009.03.015

Santhanam, G., Ryu, S. I., Yu, B. M., Afshar, A., and Shenoy, K. V. (2006). A high-performance brain-computer interface. Nature 442, 195-198. doi: 10. 1038/nature04968

Schalk, G., Kubánek, J., Miller, K. J., Anderson, N. R., Leuthardt, E. C., Ojemann, J. G., et al. (2007). Decoding two-dimensional movement trajectories using electrocorticographic signals in humans. J. Neural Eng. 4, 264-275. doi: 10. 1088/1741-2560/4/3/012

Schalk, G., and Leuthardt, E. C. (2011). Brain-computer interfaces using electrocorticographic signals. IEEE Rev. Biomed. Eng. 4, 140-154. doi: 10. 1109/RBME.2011.2172408

Schalk, G., Miller, K. J., Anderson, N. R., Wilson, J. A., Smyth, M. D., Ojemann, J. G., et al. (2008). Two-dimensional movement control using electrocorticographic signals in humans. J. Neural Eng. 5, 75-84. doi: 10. 1088/1741-2560/5/1/008

Schell, J. (2008). The Art of Game Design: A Book of Lenses. Burlington, MA: Morgan Kaufmann Publishers.

Schmidt, R. A. (2008). Motor Learning and Performance: A Situation-based Learning Approach; [Includes Access to Online Study Guide; 20 Experimental Labs]. Champaign, IL: Human Kinetics.

Schwartz, A. B., Cui, X. T., Weber, D. J., and Moran, D. W. (2006). Braincontrolled interfaces: movement restoration with neural prosthetics. Neuron 52, 205-220. doi: 10.1016/j.neuron.2006.09.019

Seger, C. A. (1994). Implicit learning. Psychol. Bull. 115, 163-196. doi: 10. 1037/0033-2909.115.2.163

Sharma, N., Pomeroy, V. M., and Baron, J. C. (2006). Motor imagery: a backdoor to the motor system after stroke? Stroke 37, 1941-1952. doi: 10.1161/01.str. 0000226902.43357.fc

Shimoda, K., Nagasaka, Y., Chao, Z. C., and Fujii, N. (2012). Decoding continuous three-dimensional hand trajectories from epidural electrocorticographic signals in Japanese macaques. J. Neural Eng. 9:036015. doi: 10.1088/17412560/9/3/036015

Skinner, B. F., and Ferster, C. B. (1997). Schedules of Reinforcement. Cambridge, MA: B.F. Skinner Foundation.

Soekadar, S. R., Witkowski, M., Birbaumer, N., and Cohen, L. G. (2014), Enhancing Hebbian learning to control brain oscillatory activity. Cereb. Cortex doi: 10.1093/cercor/bhu043 [Epub ahead of print].

Stevenson, I. H., London, B. M., Oby, E. R., Sachs, N. A., Reimer, J., Englitz, B., et al. (2012). Functional connectivity and tuning curves in populations of simultaneously recorded neurons. PLoS Comput. Biol. 8:e1002775. doi: 10. 1371/journal.pcbi.1002775

Sudre, G., Parkkonen, L., Bock, E., Baillet, S., Wang, W., and Weber, D. J. (2011). rtMEG: a real-time software interface for magnetoencephalography. Comput. Intell. Neurosci. 2011:327953. doi: 10.1155/2011/327953

Tabot, G. A., Dammann, J. F., Berg, J. A., Tenore, F. V., Boback, J. L., Vogelstein, R. J., et al. (2013). Restoring the sense of touch with a prosthetic hand through a brain interface. Proc. Natl. Acad. Sci. U S A 110, 18279-18284. doi: 10. 1073/pnas.1221113110

Taylor, D. M., Tillery, S. I., and Schwartz, A. B. (2002). Direct cortical control of 3D neuroprosthetic devices. Science 296, 1829-1832. doi: 10.1126/science.1070291

Tkach, D., Reimer, J., and Hatsopoulos, N. G. (2007). Congruent activity during action and action observation in motor cortex. J. Neurosci. 27, 13241-13250. doi: 10.1523/jneurosci.2895-07.2007

Tkach, D., Reimer, J., and Hatsopoulos, N. G. (2008). Observation-based learning for brain-machine interfaces. Curr. Opin. Neurobiol. 18, 589-594. doi: 10 1016/j.conb.2008.09.016

Truccolo, W., Friehs, G. M., Donoghue, J. P., and Hochberg, L. R. (2008). Primary motor cortex tuning to intended movement kinematics in humans 
with tetraplegia. J. Neurosci. 28, 1163-1178. doi: 10.1523/JNEUROSCI.4415-07. 2008

Tye, K. M., and Deisseroth, K. (2012). Optogenetic investigation of neural circuits underlying brain disease in animal models. Nat. Rev. Neurosci. 13, 251-266. doi: $10.1038 / \mathrm{nrn} 3171$

VanLehn, K. (1996). Cognitive skill acquisition. Annu. Rev. Psychol. 47, 513-539. doi: 10.1146/annurev.psych.47.1.513

Velliste, M., Perel, S., Spalding, M. C., Whitford, A. S., and Schwartz, A. B. (2008). Cortical control of a prosthetic arm for self-feeding. Nature 453, 1098-1101. doi: $10.1038 /$ nature 06996

Vidaurre, C., and Blankertz, B. (2010). Towards a cure for BCI illiteracy. Brain Topogr. 23, 194-198. doi: 10.1007/s10548-009-0121-6

Waldert, S., Preissl, H., Demandt, E., Braun, C., Birbaumer, N., Aertsen, A., et al. (2008). Hand movement direction decoded from MEG and EEG. J. Neurosci. 28, 1000-1008. doi: 10.1523/JNEUROSCI.5171-07.2008

Wander, J. D., Blakely, T., Miller, K. J., Weaver, K. E., Johnson, L. A., Olson, J. D., et al. (2013). Distributed cortical adaptation during learning of a braincomputer interface task. Proc. Natl. Acad. Sci. U S A 110, 10818-10823. doi: 10. $1073 /$ pnas. 1221127110

Wang, W., Chan, S. S., Heldman, D. A., and Moran, D. W. (2007). Motor cortical representation of position and velocity during reaching. J. Neurophysiol. 97, 4258-4270. doi: 10.1152/jn.01180.2006

Wang, W., Chan, S. S., Heldman, D. A., and Moran, D. W. (2010a). Motor cortical representation of hand translation and rotation during reaching. J. Neurosci. 30, 958-962. doi: 10.1523/JNEUROSCI.3742-09.2010

Wang, W., Collinger, J. L., Degenhart, A. D., Tyler-Kabara, E. C., Schwartz, A. B., Moran, D. W., et al. (2013). An electrocorticographic brain interface in an individual with tetraplegia. PLoS One 8:e55344. doi: 10.1371/journal.pone. 0055344

Wang, W., Collinger, J. L., Perez, M. A., Tyler-Kabara, E. C., Cohen, L. G., Birbaumer, N., et al. (2010c). Neural interface technology for rehabilitation: exploiting and promoting neuroplasticity. Phys. Med. Rehabil. Clin. N. Am. 21, 157-178. doi: 10.1016/j.pmr.2009.07.003

Wang, W., Sudre, G. P., Xu, Y., Kass, R. E., Collinger, J. L., Degenhart, A. D., et al. (2010b). Decoding and cortical source localization for intended movement direction with MEG. J. Neurophysiol. 104, 2451-2461. doi: 10.1152/jn.00239. 2010

Weber, D. J., Friesen, R., and Miller, L. E. (2012). Interfacing the somatosensory system to restore touch and proprioception: essential considerations. J. Mot. Behav. 44, 403-418. doi: 10.1080/00222895.2012.735283

Weber, D. J., London, B. M., Hokanson, J. A., Ayers, C. A., Gaunt, R. A., Torres, R. R., et al. (2011). Limb-state information encoded by peripheral and central somatosensory neurons: implications for an afferent interface. IEEE Trans. Neural Syst. Rehabil. Eng. 19, 501-513. doi: 10.1109/TNSRE.2011.2163145

Wei, P., He, W., Zhou, Y., and Wang, L. (2013). Performance of motor imagery brain-computer interface based on anodal transcranial direct current stimulation modulation. IEEE Trans. Neural Syst. Rehabil. Eng. 21, 404-415. doi: 10.1109/TNSRE.2013.2249111

Wessberg, J., and Nicolelis, M. A. (2004). Optimizing a linear algorithm for realtime robotic control using chronic cortical ensemble recordings in monkeys. J. Cogn. Neurosci. 16, 1022-1035. doi: 10.1162/0898929041502652

Wodlinger, B., Downey, J., Tyler-Kabara, E., Schwartz, A., Boninger, M., and Collinger, J. (2015). Ten-dimensional anthropomorphic arm control in a human brain-machine interface: difficulties, solutions and limitations. J. Neural Eng. 12:016011. doi: 10.1088/1741-2560/12/1/016011

Wolpaw, J. R., and McFarland, D. J. (2004). Control of a two-dimensional movement signal by a noninvasive brain-computer interface in humans. Proc. Natl. Acad. Sci. U S A 101, 17849-17854. doi: 10.1073/pnas.0403504101

Yanagisawa, T., Hirata, M., Saitoh, Y., Kishima, H., Matsushita, K., Goto, T., et al. (2012). Electrocorticographic control of a prosthetic arm in paralyzed patients. Ann. Neurol. 71, 353-361. doi: 10.1002/ana.22613

Yin, H. H., Mulcare, S. P., Hilárrio, M. R., Clouse, E., Holloway, T., Davis, M. I., et al. (2009). Dynamic reorganization of striatal circuits during the acquisition and consolidation of a skill. Nat. Neurosci. 12, 333-341. doi: 10.1038/nn. 2261

Yu, B. M., Cunningham, J. P., Santhanam, G., Ryu, S. I., Shenoy, K. V., and Sahani, M. (2009). Gaussian-process factor analysis for low-dimensional single-trial analysis of neural population activity. J. Neurophysiol. 102, 614-635. doi: 10. 1152/jn.90941.2008

Zaaimi, B., Ruiz-Torres, R., Solla, S. A., and Miller, L. E. (2013). Multi-electrode stimulation in somatosensory cortex increases probability of detection. J. Neural Eng. 10:056013. doi: 10.1088/1741-2560/10/5/056013

Zhang, Y., Schwartz, A. B., Chase, S. M., and Kass, R. E. (2012). Bayesian learning in assisted brain-computer interface tasks. Conf. Proc. IEEE Eng. Biol. Soc. 2012, 2740-2743. doi: 10.1109/EMBC.2012.6346531

Ziemann, U., Wittenberg, G. F., and Cohen, L. G. (2002). Stimulation-induced within-representation and across-representation plasticity in human motor cortex. J. Neurosci. 22, 5563-5571.

Conflict of Interest Statement: The Guest Associate Editor Martin Oudega declares that, despite being affiliated to the same institution as the authors, the review process was handled objectively and no conflict of interest exists. The authors declare that the research was conducted in the absence of any commercial or financial relationships that could be construed as a potential conflict of interest.

Copyright (C) 2015 Hiremath, Chen, Wang, Foldes, Yang, Tyler-Kabara, Collinger and Boninger. This is an open-access article distributed under the terms of the Creative Commons Attribution License (CC BY). The use, distribution and reproduction in other forums is permitted, provided the original author(s) or licensor are credited and that the original publication in this journal is cited, in accordance with accepted academic practice. No use, distribution or reproduction is permitted which does not comply with these terms. 